\title{
INFANT AND \\ CHILD MORTALITY IN SOUTH WARWICKSHIRE, 1962-1963
}

BY

\author{
P. M. DUNN* and M. E. MACGREGOR \\ From the South Warwickshire Hospital Group
}

(RECEIVED FOR PUBLICATION MARCH 10, 1964)

This survey is concerned with the deaths of infants and children under the age of 15 , in South Warwickshire between July 1, 1962 and June 30, 1963. It reports their age at death, where they died, and the main cause of death. Its small size is justified, it is hoped, by the belief that full ascertainment is usually only possible in populations that are small enough for the collection of data to be closely supervised by the investigator (Leck and Smithells, 1963; Leck and Record, 1963).

\section{Material and Method}

South Warwickshire (Central and Southern districts) has a population of 179,747 (Census, 1961, General Register Office, 1963) of which $52 \%$ is rural in character and $48^{\circ}$ o urban (Fig. 1). There are approximately 45,000 infants and children under the age of 15 in the area (June 1963). During the year under study, 3,510 infants were born, $58 \cdot 3^{\circ}$ of them being delivered in hospital.

The area is served by the South Warwickshire Hospital Group which is equipped to deal with practically all paediatric problems; exceptions to this are those requiring neurosurgery. During the year, 2,002 newborn babies were nursed in the 92 cots in three hospital maternity units; 808 infants and children were admitted to 54 'surgical' beds in four hospitals and a further 686 were cared for in 70 'medical' beds in two hospitals. Thus, 1,494 children (approximately 1 out of every 30 ) were admitted to hospital during the course of the year.

We decided, for the sake of greater accuracy, to report the deaths taking place within the area, rather than deaths of children who lived there but may have died elsewhere. In fact, as can be seen in Table 1, these two groups practically balance each other.

Three-quarters of the data on which this report is based was collecte concurrently. The remainder was obtained from death certificates, from post-mortem reports, and from information provided by family doctors.

Of the infants and children that died, $78^{\circ}$ were either in hospital at the time or were under hospital surveillance for the disease that was responsible for their death. Postmortem examination was carried out on $80 \cdot 2^{\circ}$ of the

- Present address: Royal Hospital for Sick Children, Bristol.

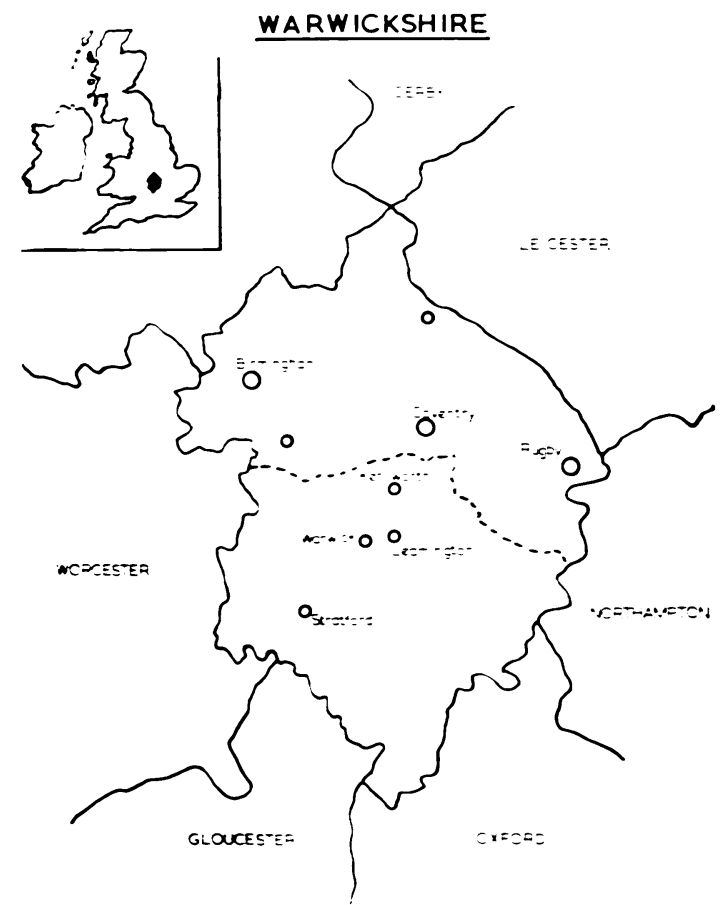

FIG. 1.-Map of Warwickshire. The area under discussion is that part of Warwickshire south of the dotted line.

TABLE 1

INFANTS AND CHILDREN BORN IN SOUTH WARWICKSHIRE (1962-1963)

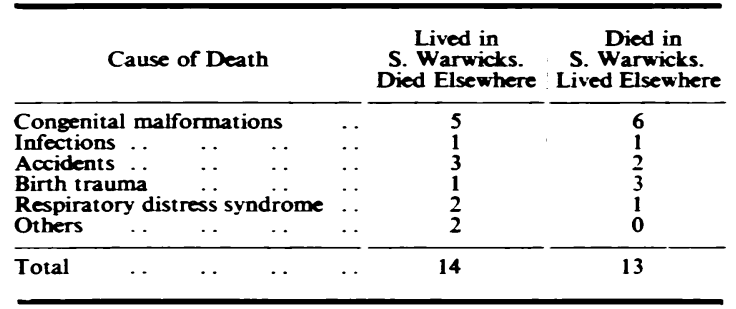




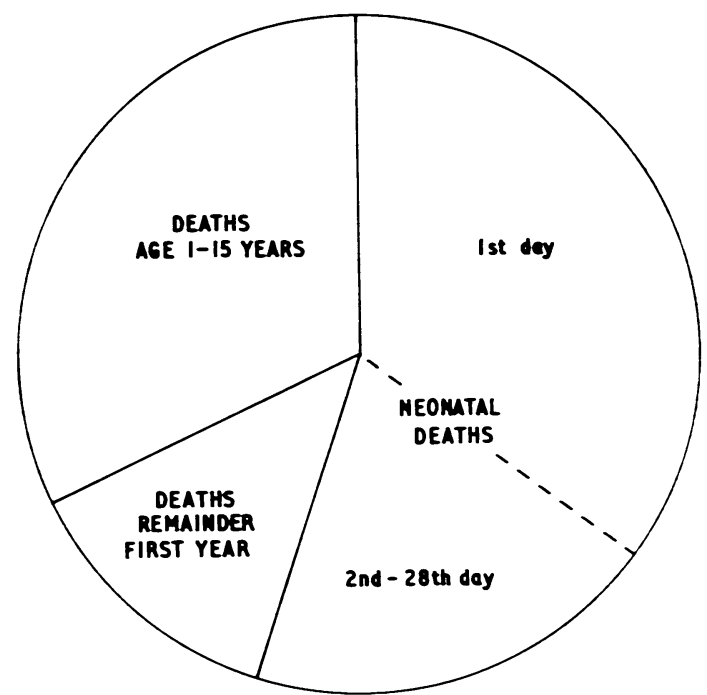

Fig. 2.-Age at death of infants and children in South Warwickshire (July 1, 1962 to June 30, 1963).

whole group. Only 3 of the infants and children who were not under hospital surveillance failed to have a necropsy.

Where more than one factor contributed towards death, the main or primary one alone was counted. Thus, a child with spina bifida who died with meningitis was claimed as a death due to congenital malformation. In only one case, an infant labelled as a resuscitation death (no necropsy), was the cause of death in doubt.

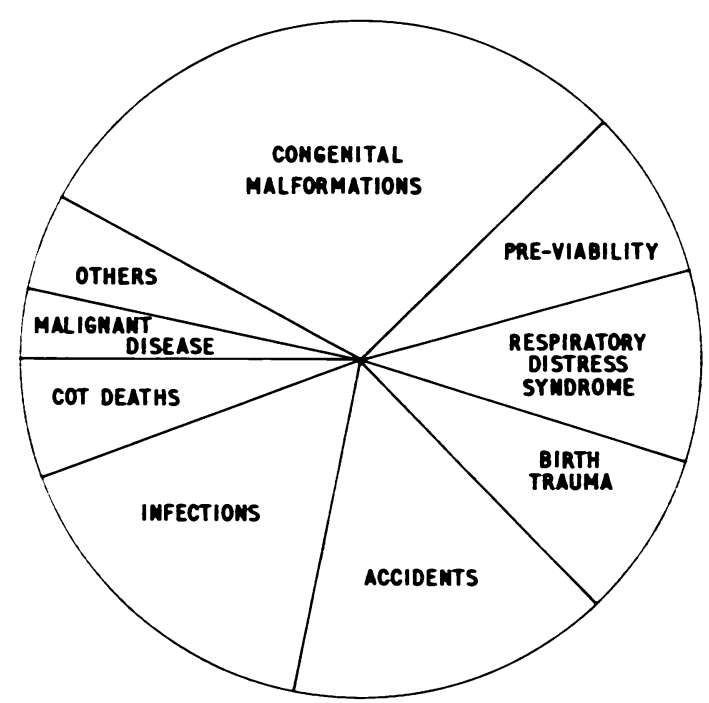

FK. 4.-Main causes of death among infants and children (ages 0-15 years) in South Warwickshire (July 1, 1962 to June 30, 1963).

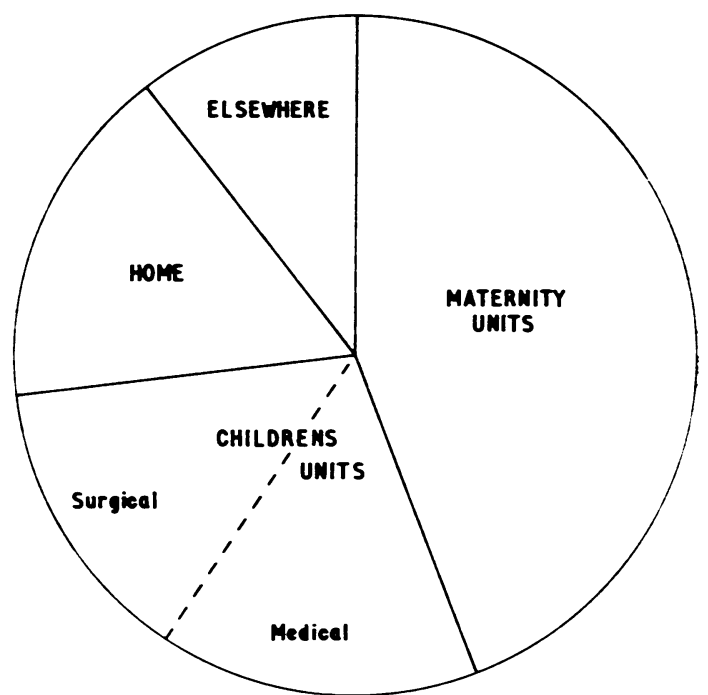

FIG. 3.-Place of death of infants and children (ages 0-15 years) in South Warwickshire (July 1, 1962 to June 30, 1963).

\section{Results}

There were 86 deaths among infants and children during the year, a mortality of 1.9 per 1,$000 ; 58^{\circ}$ o were boys and $42_{\%}^{\circ}$ girls.

Age at Death (Fig. 2). 69\% of all deaths were among infants (age 0-1), the infant mortality being $16 \cdot 9$ per 1,000 . Over half of these infant deaths

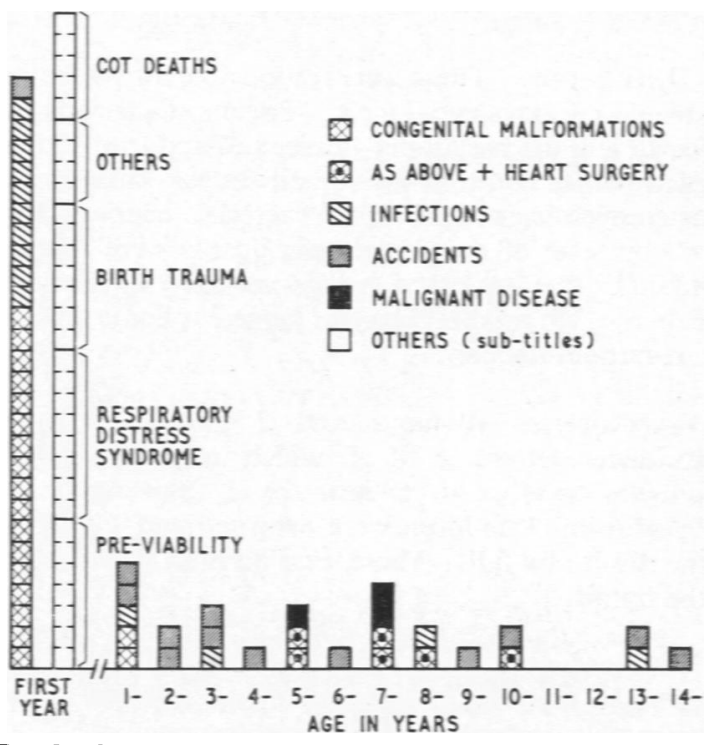

Fig. 5. - Cause of death in relation to age at death of infants and children in S suth Warwickshire (July 1. 1962 to June 30, 1963). Each square represents a death. 
took place on the first day of life and $80^{\circ} \%$ of them during the first month, the neonatal mortality being $13 \cdot 5$ per 1,000 . Deaths after the first birthday were fairly evenly spread over the remaining 14 years (see Fig. 5), the mortality rate being $0 \cdot 64$ per 1,000 .

Place of Death (Fig. 3). $44^{\circ}{ }_{o}$ of all deaths occurred in hospital maternity units, a figure that includes $81^{\circ}{ }_{0}$ of all neonatal deaths; $29^{\circ}$, died in the children's units, being evenly divided between medical and surgical beds, $16 \cdot 3 \%$ died at home, and the remaining $10 \cdot 5^{\circ}$ of deaths took place "elsewhere" in South Warwickshire.

Cause of Death. This is shown in Figs. 4 and 5.

Congenttal Malformations. These accounted for 25 deaths $\left(29^{\circ}{ }_{0}\right)$. There were 11 boys and 14 girls. Of these, 13 suffered from congenital heart disease, 5 had malformations of the central nervous system, 5 had multiple abnormalities, and the remaining 3 suffered respectively from mongolism, achondroplasia, and urethral valves. Half died within one week of birth. With the exception of deaths following cardiac surgery (6), no child died as a result of a congenital malformation after the second birthday. It should be mentioned that the presence of a regional cardiac surgical centre in this area was responsible for the weighting of this series with two more deaths from cardiac congenital malformation than would otherwise have been the case.

INFECTIONS. These were responsible for 14 deaths $\left(16 \cdot 3^{\circ}{ }_{0}\right), 7$ boys and 7 girls. Pneumonia accounted for 10 and the remaining 4 cases suffered from either gastro-enteritis, tonsillitis with status epilepticus, osteomyelitis, or subacute bacterial endocarditis. All but one of the pneumonia deaths were among infants, the majority being newborn premature babies. No infants born and nursed at home died as a result of infection.

ACCIDENTS. 10 boys and 2 girls died from accidents $\left(15 \cdot 1^{\circ}{ }_{0}\right), 9$ of which involved motor vehicles (cyclists 4 , pedestrians 3, passengers 2 ). In addition 3 children were drowned and 1 died as the result of a fall. There were no fatal accidents in the home.

Malignant Disease. This caused three deaths $\left(3 \cdot 5^{\circ}\right)$, and all were boys. Two suffered from leukaemia and one had a nephroblastoma.

Birth Trauma. This accounted for 7 deaths $\left(8 \cdot 1^{\circ}, 0\right), 5$ boys and 2 girls. Death was due to brain damage in 6 and to a ruptured liver in 1. All died within a week of birth.

Previability. This was defined as a gestation of less than 28 weeks. There were 7 deaths $\left(8 \cdot 2^{\circ}{ }_{0}\right)$, 5 boys and 2 girls; all took place during the first three days of life. The heaviest of these infants weighed 2 lb. 9 oz. (1,162 g.).

Respiratory Distress Syndrome. This was responsible for 8 deaths $\left(9 \cdot 3^{\circ}{ }_{0}\right), 5$ boys and 3 girls. All were delivered in hospital and all were born more than five weeks before term, weighed less than $5 \frac{1}{2} \mathrm{lb}$. $(2,500$ g.), and died between 7 and 24 hours after birth.

'Cot Deaths.' These were sudden, unexpected deaths among apparently healthy infants. There were 5 , all boys $\left(5 \cdot 8^{\circ}{ }_{0}\right)$. All were aged 1 to 5 months and each of these deaths took place in the home.

Other Deaths. This group consists of 4 baby girls $\left(4 \cdot 7^{\circ}\right)$ who were born in maternity units and died shortly after birth as a result of either paroxysmal tachycardia, bilateral pneumothorax, cardio-respiratory failure following severe maternal accidental haemorrhage, or failure of resuscitation.

TABLE 2

INFANTS AND CHILDREN BORN IN SOUTH WARWICKSHIRE (1962-1963)

\begin{tabular}{|c|c|c|c|}
\hline & $\begin{array}{c}\text { Stillbirth } \\
\text { Rate }\end{array}$ & $\begin{array}{c}\text { Perinatal } \\
\text { Death Rate }\end{array}$ & $\begin{array}{c}\text { Neonatal } \\
\text { Death Rate }\end{array}$ \\
\hline $\begin{array}{l}\text { Infants born at home } \\
\text { Infants born in hospital .. } \\
\text { All infants }\end{array}$ & $\begin{array}{r}4 \cdot 1 \\
22 \cdot 9 \\
15 \cdot 1\end{array}$ & $\begin{array}{r}8 \cdot 9 \\
39 \cdot 5 \\
26 \cdot 8\end{array}$ & $\begin{array}{r}5 \cdot 5 \\
19 \cdot 9 \\
13 \cdot 6\end{array}$ \\
\hline
\end{tabular}

The stillbirth, perinatal, and neonatal death rates for infants born at home and in hospital are shown in Table 2. The perinatal mortality for all births was $26 \cdot 8$ which is approximately 6 per 1,000 less than the national average.

In passing, tribute must be paid to the midwives and family doctors who achieved the remarkably low perinatal mortality of 8.9 per 1,000 for deliveries outside hospital units.

\section{Discussion}

The care of infants and children is shared by family doctors, obstetricians, surgeons in a wide range of special fields, and paediatricians. Surveys such as this enable an over-all assessment of the 
relative importance of the causes of death in infancy and childhood.

South Warwickshire contains (and also gives birth to) approximately one three-hundredth of the infant and child population of England and Wales. If the findings of this survey are reasonably representative, and there is evidence from more than one source to suggest they are, then crude mortality statistics for England and Wales may be obtained by multiplying these South Warwickshire results by 300 .

Thus, the 5 'cot deaths' in South Warwickshire become 1,500 for England and Wales. This figure is very similar to that of 1,400 given by Banks (1958) for the year 1955. The cause of these 'cot deaths' remains an enigma (Valdés-Dapena, 1963), though recent work on sensitivity to cows milk (Parish, Barrett. Coombs, Gunther, and Camps, 1960) has opened up a new line of investigation. In the meantime they remain perhaps the most frequent, tragic, and inaccessible form of death in infancy after the first month of life.

For many causes of death, such as accidents, birth trauma, or extreme prematurity, prevention is better than cure because often there is no cure. For others, such as congenital malformations or malignant diseases, even prevention may have to wait on further knowledge. However, some causes of death are, in part, both preventable and treatable. The most important of these are infections and the respiratory distress syndrome of the newborn. Together they were responsible, in this survey, for a quarter of all deaths and for $37^{\circ}$ o of those in the neonatal period. It is in the hospital maternity units that they take their greatest toll. The National Survey of Perinatal Mortality (1961) has already drawn attention to, and this survey confirms, the enormous number of deaths occurring during the first few days of life. Though the neonatal mortality reported for South Warwickshire is lower than the national average, simple calculation based on it shows that the chance of dying during the first month of life was 292 times greater than during any month in childhood. When the first day of life is considered, the danger was no less than 5,676 times as great. A large part of neonatal paediatrics is of an emergency nature. The interval between birth or onset of symptoms, and death can usually be measured in minutes and hours rather than days. In addition, treatment for a disease such as respiratory distress syndrome of the newborn may be extremely time consuming (Hutchison, Kerr, McPhail, Douglas, Smith, Norman, and Bates, 1962). Most neonatal nurseries are very understaffed. South Warwickshire, in common with much of the country, has no member of the paediatric staff resident in any of its maternity units. Correction of this state of affairs would probably go further towards reducing infant mortality than any other single factor.

\section{Summary}

During the space of a year, there were 86 deaths among 45,000 infants and children in South Warwickshire.

Data concerning age at death, place of death, and reason for death, are presented.

Over half the deaths took place among infants in the first month of life and $81^{\circ}$, of these died in hospital maternity units.

These figures were compiled with help from a number of people, and we would like to thank in particular the Area Medical Officers of Health and consulting pathologists.

\section{REFERENCES}

Banks. A. L (1958). An enquiry into sudden death in infancy. Mth. Bull. Minist. Hith Lab. Serv.. 17. 182

General Register Office (1963). Census. 1961. England and Wales. Populations, Dwellings and Households in Staffordshire. Warwickshire and Worcestershire. Leaflet No. 8. H.M. Stationery Office. London.

Hutchison. J. H.. Kerr. M. M.. McPhail. M. F. M.. Douglas. T. A. Smith. G.. Norman. J. N.. and Bates. E. H. (1962). Studies in the treatment of the pulmonary syndrome of the newborn. Lancet. 2. 465.

Leck. I., and Record. R. G. (1963). Sources of variation in the reporting of malformations. Develop. Med. Child Neurol.. 5. 364 and Smithells. R. W. (1963). The ascertainment of malformations. Lancet, 1. 101.

National Survey of Perinatal Mortality (1961). First results. Brit. med. J.. 1. 1313.

Parish. W. E.. Barrett. A. M., Coombs. R. R. A.. Gunther. M.. and Camps. F. E. (1960). Hypersensitivity to milk and sudden death in infancy. Lancet. 2. 1106.

Valdes-Dapena. M. A. (1963). Sudden and unexpected death in infants. The scope of our ignorance. Pediat. Clin. N. Amer. 10,693 . 